\title{
Virtual or real: lifelike cinematic rendering of adrenal tumors
}

\author{
Lei Tang ${ }^{1,2 \#}$, Yuquan Wang ${ }^{2 \#}$, Xiushu Yang ${ }^{3} \wedge$, Guangheng Luo ${ }^{3}$, Xianchun Zeng $^{2} \wedge$, Rongpin Wang $^{2}$, \\ Bin Song ${ }^{1 \wedge}$
}

${ }^{1}$ Department of Radiology, West China Hospital, Sichuan University, Chengdu, China; ${ }^{2}$ Department of Radiology, Guizhou Provincial People's Hospital, Key Laboratory of Intelligent Medical Imaging Analysis and Accurate Diagnosis of Guizhou Province, International Exemplary Cooperation Base of Precision Imaging for Diagnosis and Treatment, Guiyang, China; ${ }^{3}$ Department of Urological Surgery, Guizhou Provincial People's Hospital, Guiyang, China

\#These authors contributed equally to this work.

Correspondence to: Bin Song. Department of Radiology, West China Hospital, Sichuan University, No. 37 Guoxue Alley, Wuhou District, Chengdu 610041, China. Email: songlab_radiology@163.com.

\begin{abstract}
The adrenal gland is small in size and hidden in location. Adrenal tumors are relatively difficult to diagnose due to the wide variety of tumors and partial overlap of image features. Cinematic rendering (CR) is a novel, three-dimensional post-processing technology that simulates how light propagates in the real world, providing high-resolution visualizations that truly present subtle anatomical details. We retrospectively collected a series of pathologically confirmed adrenal tumor cases, raw data was introduced into the post-processing workstation, and different tools and templates of CR software were used for reconstruction and rendering. Compared with traditional black and white two-dimensional images and three-dimensional volume rendering (VR) images, CR images were more colorful, layered, and closer to the truth. CR has potential in diagnosing and preoperative planning of adrenal tumors, allowing vivid and realistic visualization of tumor location, morphology, different components (solid, cystic, fat, calcification, etc.), the pattern of enhancement, and the relationship with surrounding tissues and organs.
\end{abstract}

Keywords: Adrenal tumor; cinematic rendering; computed tomography (CT); 3D visualization

Submitted Nov 19, 2020. Accepted for publication Mar 26, 2021.

doi: $10.21037 /$ qims-20-1282

View this article at: http://dx.doi.org/10.21037/qims-20-1282

\section{Introduction}

Adrenal tumors are relatively common clinically, with a detection rate of about $4 \%$ in abdominal computed tomography (CT) examinations and $6 \%$ at autopsy $(1,2)$. As the main imaging modality, CT can clearly show the location, shape, size, margin, density, enhancement characteristics, and the adjacent relationship with the tumor's surrounding tissues and organs. Adrenal CT scanning protocol generally recommends an initial lowdose, non-enhanced CT scan with a thin slice $(2-3 \mathrm{~mm})$ and reconstructed in the axial and coronal planes (3). If the lesion does not have benign imaging features, including significant lipid component and attenuation value $<10$ Hounsfield units [HU], further dynamic enhancement scans (including early arterial, venous, and delayed phases) are performed $(4,5)$.

Compared to traditional two-dimensional multiplane

^ ORCID: Lei Tang, 0000-0003-1582-1023; Yuquan Wang, 0000-0002-3546-2905; Xiushu Yang, 0000-0001-9423-0648; Xianchun Zeng, 0000-0003-0857-3834; Rongpin Wang, 0000-0001-7587-4181; Bin Song, 0000-0002-7269-2101. 
recombination (MPR) images, the three-dimensional volume rendering (VR) technique adopts more complex algorithms based on the principle of ray casting and local illumination and introduces colors to show different anatomical structures of a body part. It allows analysis of structures in different $\mathrm{CT}$ value units, highlighting the tissue type, density, location, and surrounding relationships, improving the $3 \mathrm{D}$ visualization of tumors, blood vessels, and anatomical details $(6,7)$. Over the past decade, 3D VR technology has been widely used in diagnosing and preoperative planning of various clinical diseases, including cardiovascular diseases, and has shown excellent application value. In coronary $\mathrm{CT}$, low-dose enhancement scans combined with VR reconstruction produced good image quality, which could easily and clearly show coronary artery variants and coronary artery disease $(8,9)$.

In 2016, a more advanced 3D post-processing technology than VR was introduced. Cinematic rendering (CR) is based on light trajectory methods and a global illumination model (10) inspired by highly realistic animated characters in anime movies. CR technology simulates light reflection and irradiation effects such as refraction, reflection, and shadow in different directions in the real world, achieving a perfect fusion of light and shadow, and has been gradually applied to the medical field (11). In terms of its imaging principle, the Monte Carlo equation is applied to construct a model that simulates the propagation and interaction of billions of photons in a random light path as they pass through volume data to form a single pixel, ultimately yielding a more realistic 3D image than the standard VR (7). Compared with the single-pixel, single-light VR, CR images' lighting and shading effects are more natural and realistic, giving the observer a visual experience and morphological perception close to the real world (12). Since 2018, some reports have described CR technology's value for the liver, spleen, pancreas, gastrointestinal tract, and cardiovascular system and have confirmed its potential to display complex anatomical structures more accurately with promising clinical applications (13-18). However, the potential value of CR for adrenal lesion imaging has not been reported.

In this pictorial review, we present CR images of some common and rare cases of adrenal tumors, demonstrating CR's role in the diagnosis and evaluation of adrenal lesions. All raw volume CT data were obtained from Siemens CT scanners (SOMATOM Definition AS or SOMATOM Force), and the images were processed by syngo.via software in $M M$ reading mode.

\section{Normal adrenal anatomy}

The adrenal glands are located in the retroperitoneal space, anteriorly above the upper pole of both kidneys, renal fascia, and abundant fat. They are usually an inverted Y-shape on CT and composed of three parts: a body, medial limb, and lateral limb. The left adrenal gland is adjacent to the pancreas' tail, spleen, stomach, and left kidney, and the right adrenal gland is adjacent to the right lobe of the liver, duodenum, inferior vena cava, and right kidney (19-21).

The gland is composed of a cortex and medulla, the former originating in the mesoderm and the latter in the ectoderm, and the histomorphology and function of the two differ. The cortex is divided into three layers from the outside to the inside: a zona glomerulosa, fasciculate, and reticularis. The zona glomerulosa produces the mineralocorticoid aldosterone that regulates electrolyte, water, and sodium metabolism, while the zona fasciculate secretes glucocorticoids, specifically cortisol, that regulate sugar and protein metabolism. Finally, the zona reticularis is the site of the production of sex hormones, mainly androgens, and to a lesser extent estrogen. The adrenal medulla is made up almost entirely of pheochromocytes which secrete adrenaline, and norepinephrine, which are collectively known as catecholamines $(4,19)$.

\section{Benign adrenal tumors}

Benign adrenal tumors are most common in adenoma and pheochromocytoma, with the former originating in the cortex and the latter mostly occurring in the medulla. Other less common benign adrenal tumors are myelolipoma, hemangioma, ganglioneuroma, schwannoma, and fibroma.

\section{Adrenal adenoma}

Adenomas are the most common adrenal tumors, usually occur unilaterally, and are most often solitary. The tumors are usually small (less than $4 \mathrm{~cm}$ in diameter), are round or oval with smooth margins, and while some have endocrine function, others are nonfunctional. Plain CT density correlates with cytoplasmic lipid content, and high lipid content results in low density. Low tumor density (unenhanced attenuation less than $10 \mathrm{HU}$ ) is specific to benign adenomas because their cytoplasm is filled with lipidlike particles or vacuoles $(22,23)$. Lesions with attenuation greater than $10 \mathrm{HU}$ may undergo further dynamic enhancement scans, and those with a benign washout pattern are considered benign lesions $(24,25)$. However, 

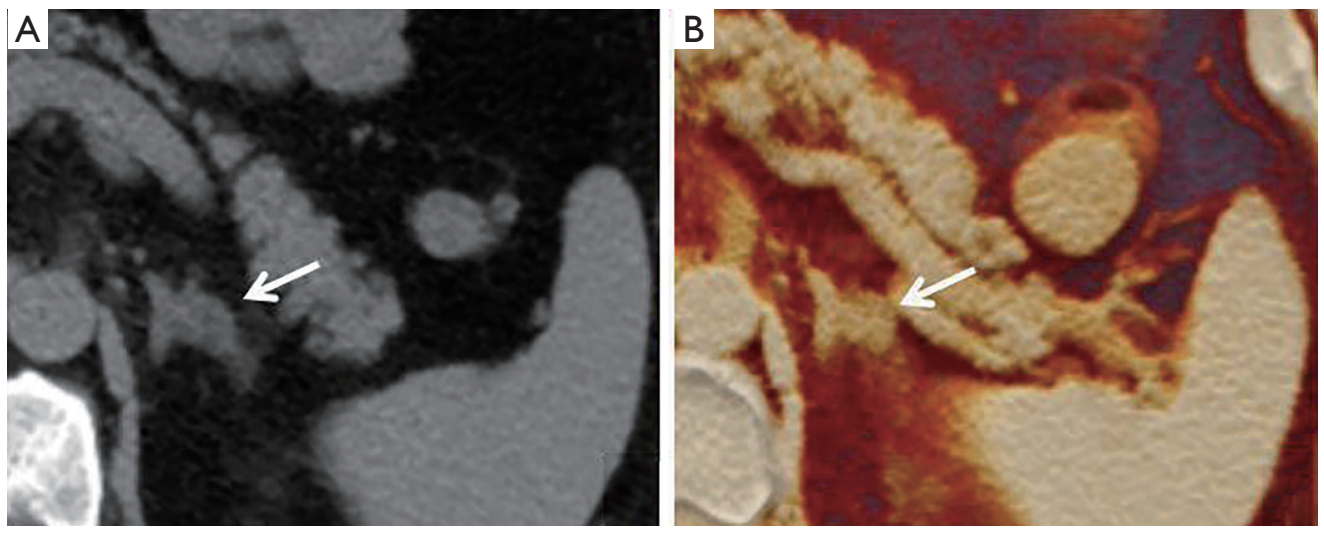

Figure 1 A 50-year-old man with left adrenal adenoma. (A) Axial unenhanced CT shows a round nodule (arrow) in the left adrenal gland with an attenuation value of 4 HU. (B) Cinematic rendering (CR) image in the same plane shows the left adrenal nodule more clearly (arrow).

as the adrenal gland is small and hidden in location, and some tumors are too small to be displayed by unenhanced CT, their diagnosis is often missed. VR technology rarely uses unenhanced CT data to reconstruct soft tissue lesions because of its lack of image resolution. CR technology can process enhanced or unenhanced CT data and perform a color display at axial, coronal, sagittal, and even arbitrary angles, clearly separate adrenal tissue and adrenal nodules from surrounding tissues, and vividly display the different components within the nodules, facilitating the detection and diagnosis of adenomas (Figures 1 and 2).

\section{Pheochromocytoma}

Pheochromocytomas are derived from catecholamineproducing chromaffin cells, and the clinical presentations are mainly paroxysmal hypertension and metabolic disorders (26). Elevated metanephrine levels and normetanephrine in plasma or 24-hour urine are the most accurate diagnostic criteria $(27,28)$. While $90 \%$ of pheochromocytomas occur in the adrenal medulla, approximately $25 \%$ are nonfunctional, patients are asymptomatic, and most tumors are found incidentally (29). Malignant transformation may occur in $10-17 \%$ of tumors, showing irregular morphology and poorly defined borders, combined with local infiltration of adjacent tissues or distant metastases (30). On CT, pheochromocytomas are usually large in size and can develop cystic changes, necrosis, and hemorrhage leading to an inhomogeneous density with a few associated calcifications. Attenuation on unenhanced CT is most often greater than $10 \mathrm{HU}$, with moderate to marked enhancement after contrast injection, and more than $60 \%$ contrast loss is demonstrated on a 15 -minute delayed scan $(31,32)$. CR reconstruction can emphasize the enhancement pattern by highlighting the enhanced tissues inside the lesion, and adjusting the window width and level helps distinguish the cystic necrotic area and fibrous septum within the tumor (Figure 3).

\section{Myelolipoma}

Myelolipoma is a rare, nonfunctional, benign tumor, the pathogenesis of which may be the metaplasia of capillary reticuloendothelial cells. Histologically, it consists of a mixture of mature bone marrow components and adipose tissue in varying proportions (33). Patients are usually asymptomatic and may experience abdominal pain when the tumor is large enough to compress adjacent organs. The tumors are mostly solitary, larger than $3 \mathrm{~cm}$ in size, rounded, and may be lobulated, with some fibrous separation visible. The foci are of uniform or inhomogeneous low density, mostly of mixed density, with clear borders. While some calcifications (about 20\%) are visible, either spotted or eggshell-like, after enhancement, the soft tissue composition inside the mass is enhanced, while the fat part is not. In brief, the presence of low-density fat is the characteristic CT manifestation of this disease $(34,35)$. The CR software is configured with a library of templates in different colors and suitable for different parts of the body and different tissues and organs, which personalizes the display of lesions in all parts of the body. Different tissue components have different densities due to different CT 

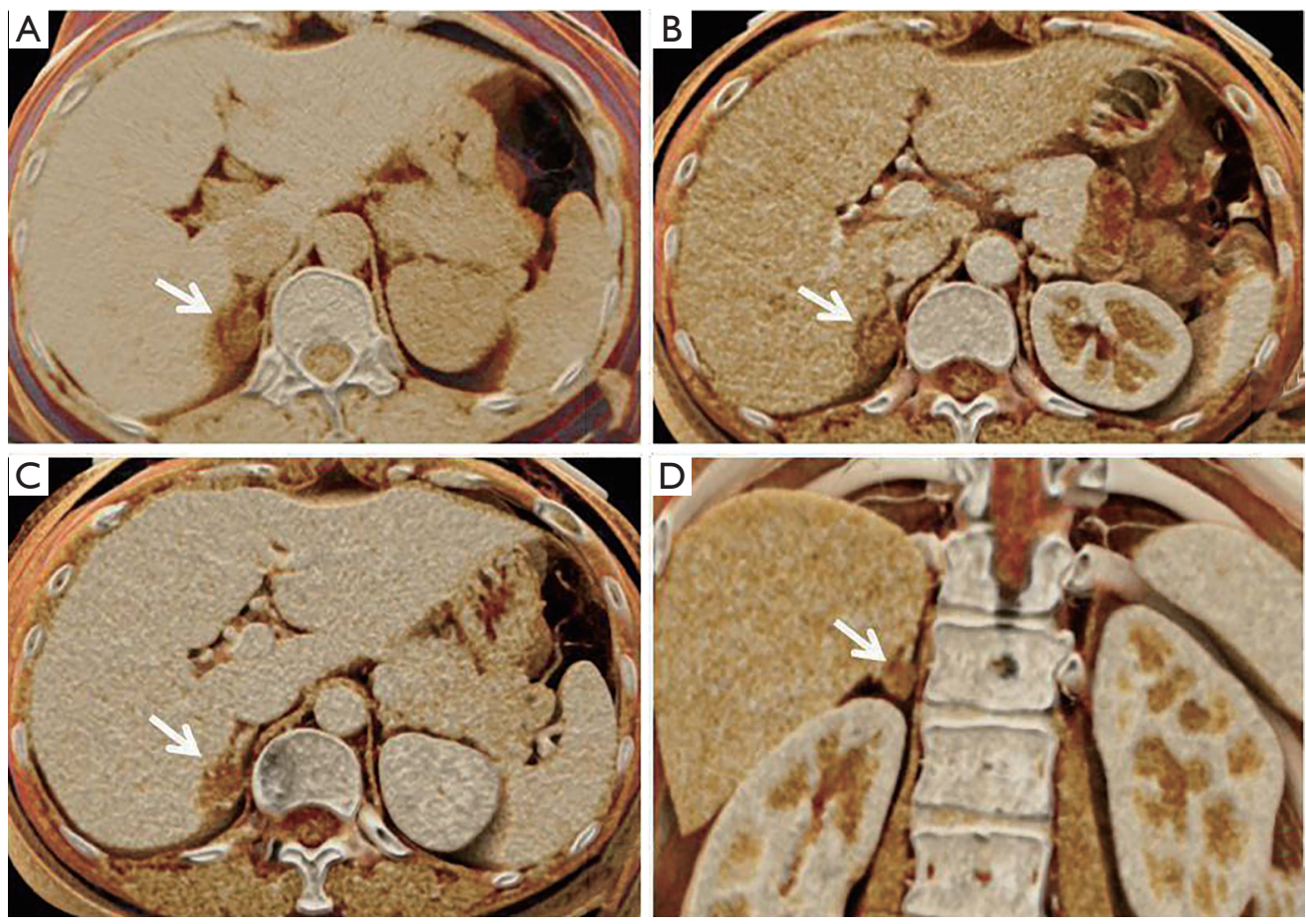

Figure 2 A 34-year-old woman presented with hypertension for 3 months. (A) Axial unenhanced CT shows an oval low-density nodule (arrow) on the right adrenal gland, approximately $16 \mathrm{~mm} \times 11 \mathrm{~mm}$ in size, with an attenuation value of 9 HU. (B,C) Arterial and venous phases: mild enhancement of the nodule margin. (D) Coronal CR image. Postoperative pathology revealed an adrenal adenoma.
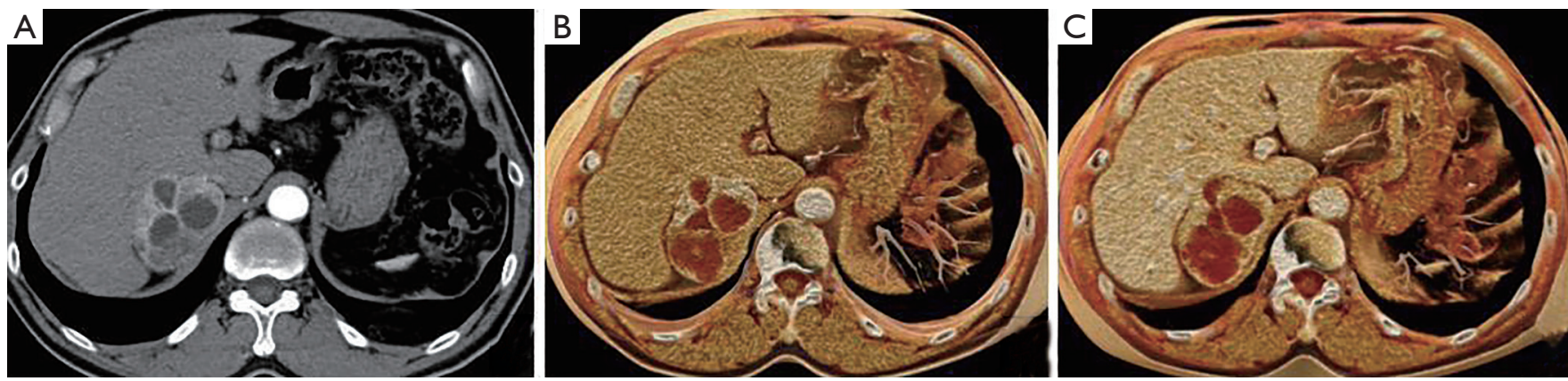

Figure 3 Pheochromocytoma. A 58-year-old male with hypertension. (A) Arterial phase CT reveals a large solid-cystic mass in the right adrenal gland. It is multilocular cystic with multiple fiber septa. The solid components are significantly enhanced. (B,C) CR images highlight the enhancement pattern, and demonstrate the cystic necrotic area and fibrous septum within the tumor.

attenuation and can be presented in different colors by CR. For example, in myelolipoma, the fat composition inside the tumor is consistent with the density of subcutaneous fat and abdominal fat, which can be displayed more intuitively by CR technology and has a good teaching demonstration effect on junior clinicians and radiologists (Figure 4).

\section{Hemangioma}

Hemangioma is a common benign tumor originating from mesenchymal tissues, mostly congenital, and can occur in many parts of the body. Pathologically, hemangiomas are classified into cavernous, capillary, venous, epithelioid, 

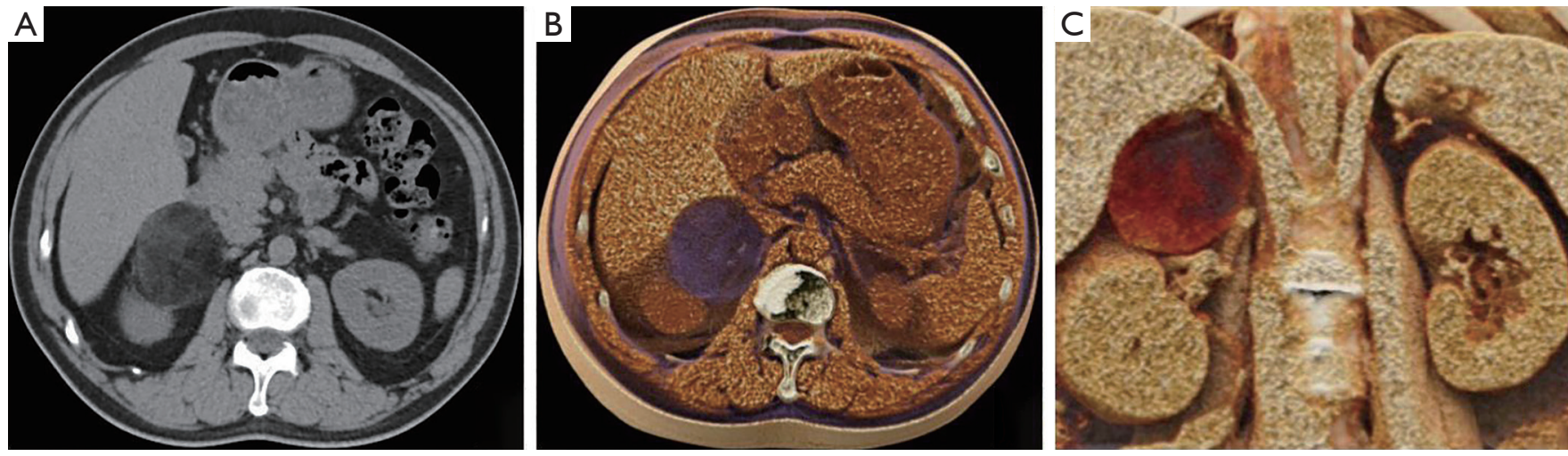

Figure 4 A 51-year-old man with right adrenal myelolipoma. (A) Axial unenhanced CT. (B) Axial CR rendered image (purple template): the right adrenal mass, abdominal fat, and subcutaneous fat all appear purple. (C) Coronal CR rendered image.
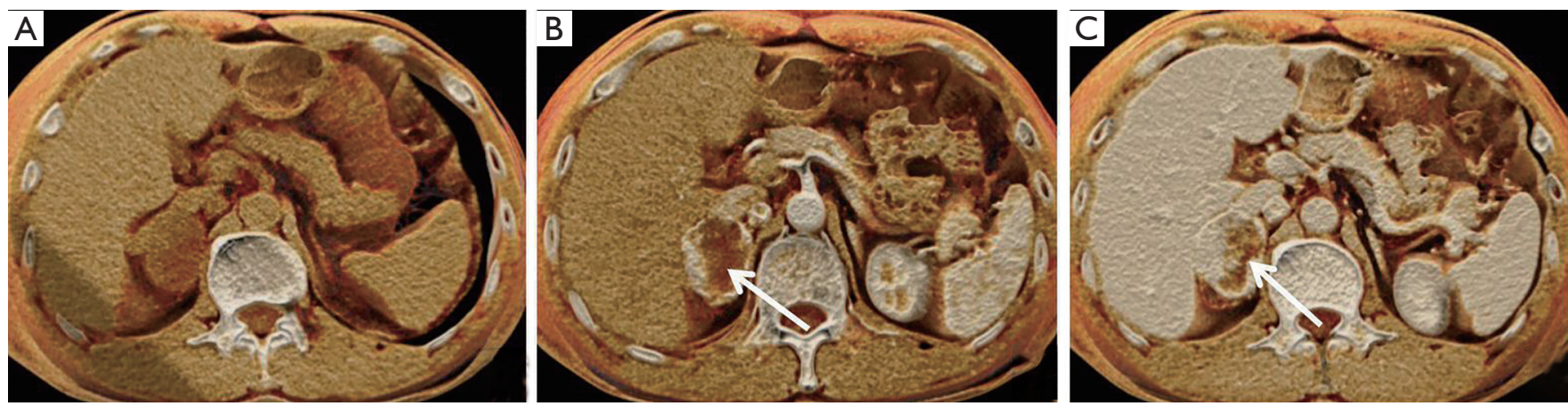

Figure 5 Cavernous hemangioma. A 49-year-old male with right lower back pain for 2 years. (A) Unenhanced abdominal CT. (B,C) In the arterial phase, nodular enhancement is seen at the edges of the tumor, and in the venous phase, the enhancement is extended and fills in towards the center (arrow).

granuloma, and other rare types. Adrenal cavernous hemangioma is a non-functional tumor with few malignant changes, which is rare and usually unilateral. Its clinical symptoms usually relate to tumor compression of surrounding organs, but there are also reports of hypertension, hyperaldosteronism, subclinical Cushing's syndrome, spontaneous rupture, and hemorrhage (36). The CT presentation is similar to that of hepatic cavernous hemangiomas, with the most diagnostic significance being the progressive enhancement pattern. This sees nodular and patchy enhancement of the lesion margins in the arterial phase, followed by a gradual widening of the extent and centripetal filling and complete filling with contrast agents in the delayed phase (37). CR images have a higher sense of realism and detail, emphasizing the typical progressive enhancement pattern of cavernous hemangioma, showing areas of enhancement at the edge of the lesion and within it in highlighted color (Figure 5).

\section{Schwannoma}

Schwannoma is a rare benign tumor originating from nerve sheath cells in the nerve ectoderm, accounting for less than $1 \%$ of adrenal lesions. It is often clinically asymptomatic, often found incidentally, more common in women, and has a median detection age of 50 years (38). Histologically, there are two main structures: Antoni A, composed of chromatin-rich spindle cells, and Antoni B, which is less cellular and rich in mucus. The distribution and proportion of Antoni $\mathrm{A}$ and $\mathrm{B}$ regions in the tumor varies, resulting in different CT densities, while the cystic changes are evident when the mucus matrix is abundant. Some lesions have 

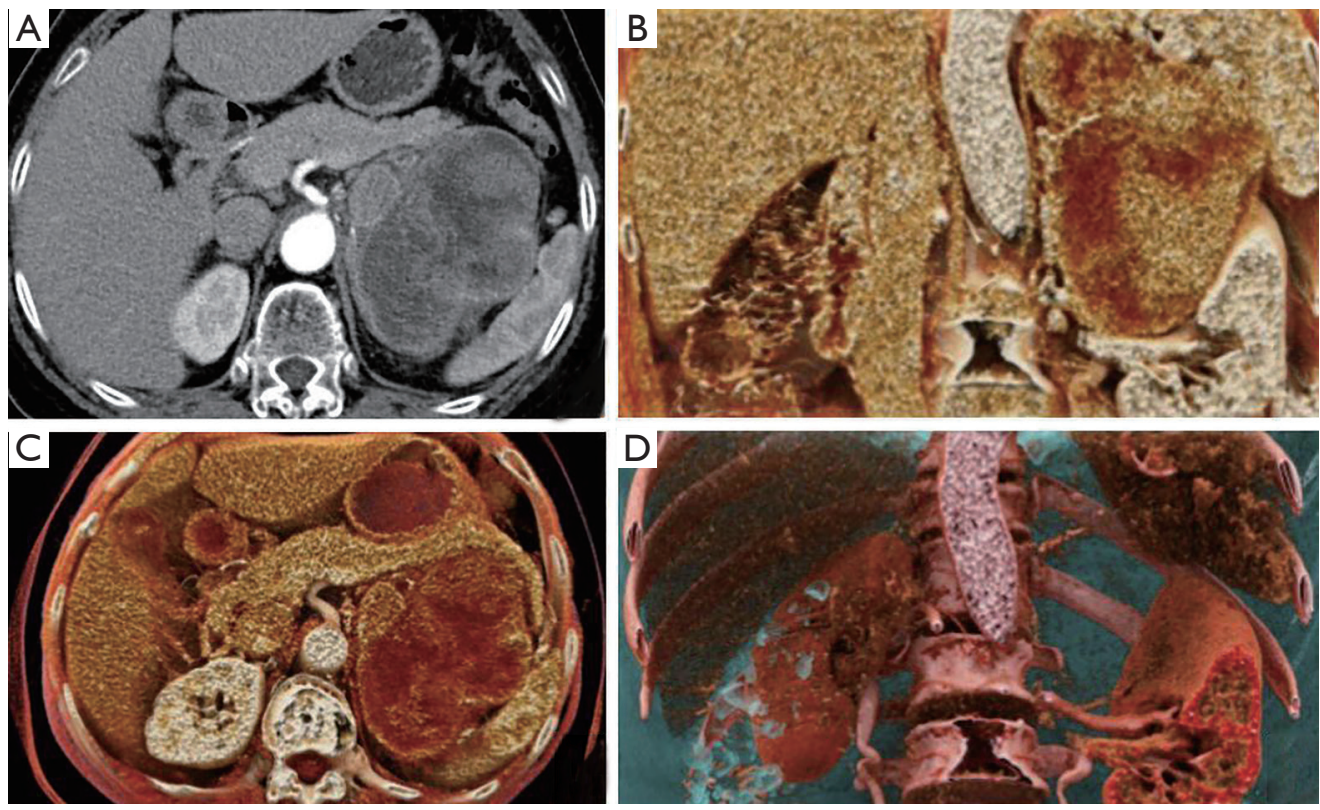

Figure 6 Schwannoma. A 64-year-old woman, in whom physical examination revealed a left adrenal mass. (A,B) Transverse location: arterial phase CT exhibits a giant lobulated mass of the left adrenal gland, with uneven density and low-density cystic lesions. (C) Coronal position: the tumor is located in the left retroperitoneal area, the spleen is compressed upward, and the left kidney is compressed downward. (D) After concealing the left adrenal mass, the surrounding tissues, organs, blood vessels, and bones can be more clearly displayed.

spotted calcification, but calcification has no diagnostic specificity (39). Adrenal schwannoma is a tumor with poor blood supply. It shows mild peripheral enhancement in the early stage and mild to moderate enhancement of the solid portion of the lesion in the venous and delayed stages $(38,40)$. By adjusting the window width, CR techniques allow for a clearer and more vivid highlighting of the mucus-rich Antoni A region (low-density region) and the cell-rich Antoni B region (equal or slightly higher density) of the tumor. The tumor is usually large in size and has a compression effect on the surrounding tissues and organs, leading to changes in their morphology and location. The use of a semi-transparent template can conceal the lowdensity tumor and spatially highlight the lesion's location and changes in its surrounding structures, contributing to preoperative localization and evaluation (Figure 6).

\section{Malignant adrenal tumors}

\section{Adrenocortical carcinoma}

Adrenocortical carcinoma is rare in clinical practice, with functional and non-functional carcinoma each accounting for about half of the cases, and the functional manifestation often Cushing's syndrome. The average age of detection is between 40 and 50 years old, and the tumor has a 1.5:1 ratio of females to males, perhaps related to the role of estrogen (17b-estradiol) in tumorigenesis $(41,42)$. Mostly unilateral, the tumor is large (more than $5 \mathrm{~cm}$ ) and prone to hemorrhage, necrosis, cystic degeneration, and, in a few cases, calcification. Unlike adenomas, the tumor can easily penetrate the envelope and invade surrounding tissues and organs with irregular morphology accompanied by the formation of an intravascular cancer plug. Adrenocortical carcinoma often metastasizes to the liver, lymph nodes, lung, brain, and other places at an early stage (43). Tumor tissues on enhancement CT are poorly enhanced or show an irregular intensification and peripheral ring, with a slow decrease in intensity during the delayed phase (44). Although adrenocortical carcinoma is difficult to distinguish from pheochromocytoma because of its inconspicuous imaging features, CR can overcome the shortcoming of insignificant tumor enhancement and emphasize the small arterial blood supply and enhancement area within the lesion, allowing radiologists to analyze its enhancement features (Figure 7). Furthermore, color rendering at 

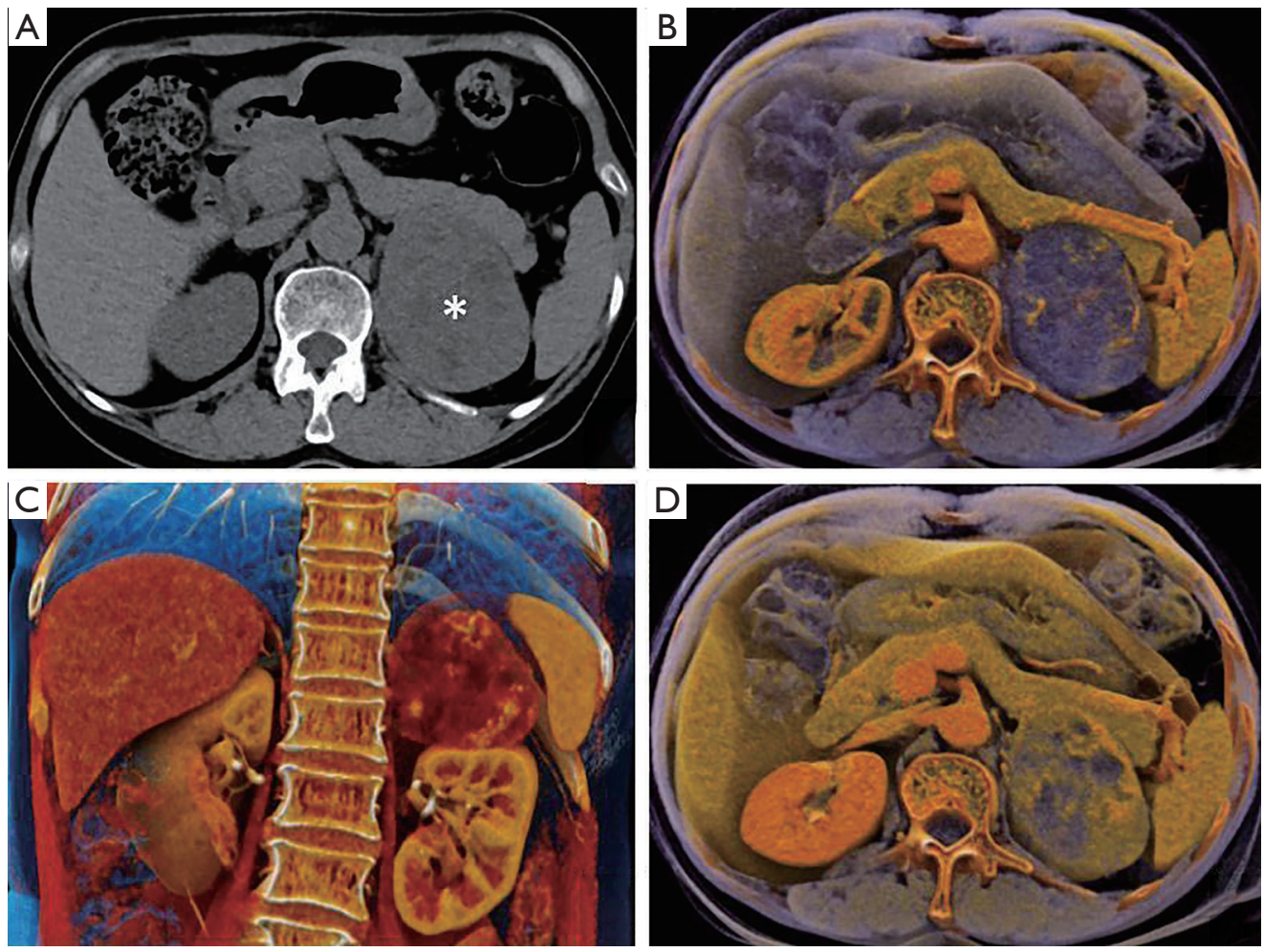

Figure 7 Adrenocortical carcinoma. A 54-year-old female with a left adrenal mass on physical examination. (A) Unenhanced CT reveals an oval mass in the left adrenal region, posterior to the pancreas' tail, with inhomogeneous density (white star). (B) In the arterial phase, tortuous and thickened small vessels can be seen inside the tumor. A residual fatty gap between the mass and the pancreatic tail is seen with a fine linear low-density shadow, suggesting that the tumor is not from the pancreas. (C) Coronal CR image clearly shows the relationship between tumor and surrounding tissues and organs. (D) In the venous phase, the tumor's solid components are uniformly enhanced, and a few areas of cystic changes are seen internally.

either angle provides a more realistic view of the tumor's infiltration of surrounding tissues and organs.

\section{Neuroblastoma}

Neuroblastoma accounts for $10 \%$ of childhood tumors and occurs primarily in the adrenal medulla (49\%) or retroperitoneal sympathetic ganglia $(30 \%)$, followed by the posterior mediastinal, cervical, and visceral sympathetic ganglia. The tumor can also occur in subcutaneous tissues and at multiple sites (45). It is more common in infants and young children, $80 \%$ of whom are under 5 years of age and $50 \%$ of whom already have liver, lymph node, and bone metastases at the time of initial diagnosis. The clinical presentation is usually a painless mass, and due to the early onset of metastasis, is accompanied by a variety of manifestations such as anemia, weight loss, low fever, and enlarged lymph nodes. If bone metastases are present, patients present with bone pain and dyskinesia (46). On imaging, the tumor is usually an irregular, solid soft tissue mass with large volume, often combined with hemorrhage, necrosis, or calcification. The most common form of calcification is punctiform, but it can also be ringshaped or patchy and is more obvious after chemotherapy. A few tumors are of uniform soft tissue density without calcification making diagnosis difficult, and when the tumor involves the adjacent kidneys, differentiation from nephroblastoma can be a major challenge (47).

In 2009, the International Neuroblastoma Risk Group (INRG) developed the preoperative imaging staging system [INRG Staging System (INRGSS)], which indicates that CT and/or MR can be used to diagnose and differentiate tumors before surgery or other treatments and to assess Image-Defined Risk Factors (IDRFs). Points to be 

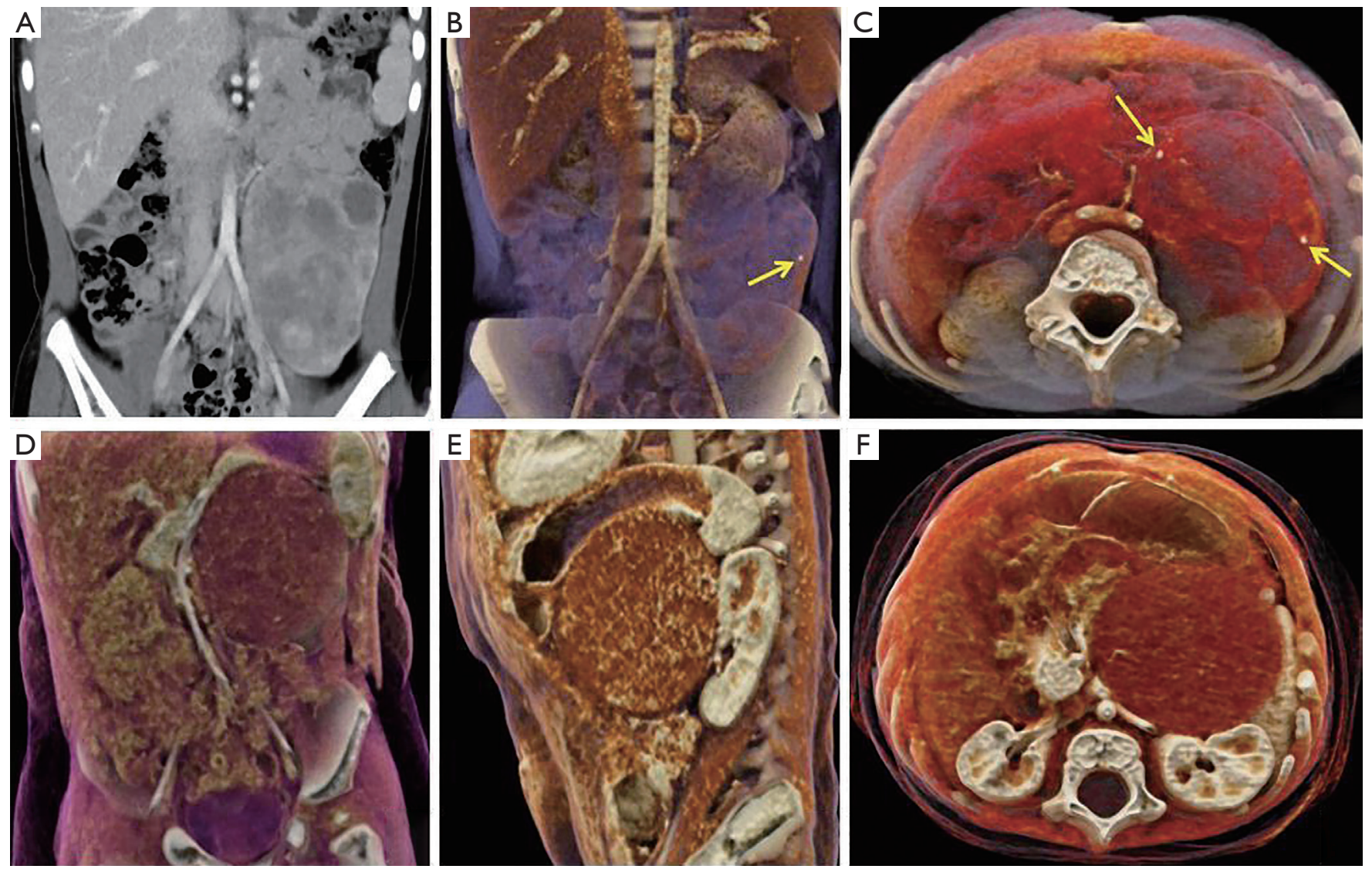

Figure 8 Neuroblastoma. (A,B,C) A 3-year-old female child with an abdominal mass. Coronal CT image exhibits a large mass with inhomogeneous density, multiple areas of low-density liquefied necrosis inside, and its inferior border in contact with the left common iliac artery. Translucent CR highlights in the same plane the subtle pitting calcification (yellow arrows) inside the mass. (D,E,F) A 7-monthold male infant with an abdominal mass. CR images display a huge soft tissue mass in the left retroperitoneal area. The intestinal tract and superior mesenteric artery are shifted to the right, the left kidney is compressed to shift backward, and the left renal artery is in contact with the mass's posterior margin.

evaluated include the location and number of primary tumors, localized or distant metastases, and whether there is a visible layer between the tumor and normal tissue (contact, encasement, infiltration, or invasion between the two). When the tumor infiltrates or encircles surrounding tissues, organs, or vessels, IDRFs are considered positive $(48,49)$. CR has great advantages in displaying fine anatomical structures and can show the whole tumor in the same plane and highlight the different tissue components within it, especially the fine calcification of neuroblastoma (Figure 8). Also, CR can be used to characterize the primary tumor, evaluate the relationship between tumor and surrounding tissues, and assess preoperative tumor staging and IDRFs, to achieve accurate medical treatment.

\section{Lymphoma}

Adrenal lymphoma is rare, mostly non-Hodgkin lymphoma (NHL), and may be unilateral or bilateral. Most commonly seen in the elderly, the clinical manifestations are not typical and may be fever, fatigue, and generalized superficial lymph node enlargement (50). The tumor presents as a soft tissue mass with a more uniform density and a moderate degree of enhancement (51) and may be accompanied by enlarged retroperitoneal lymph nodes and invasion of the liver and skin. If there is diffuse infiltration of the spleen or kidney, lymphoma is strongly suggested. CR post-processing shows the location, morphology, density, enhancement pattern, extent of involvement, and depth of infiltration 

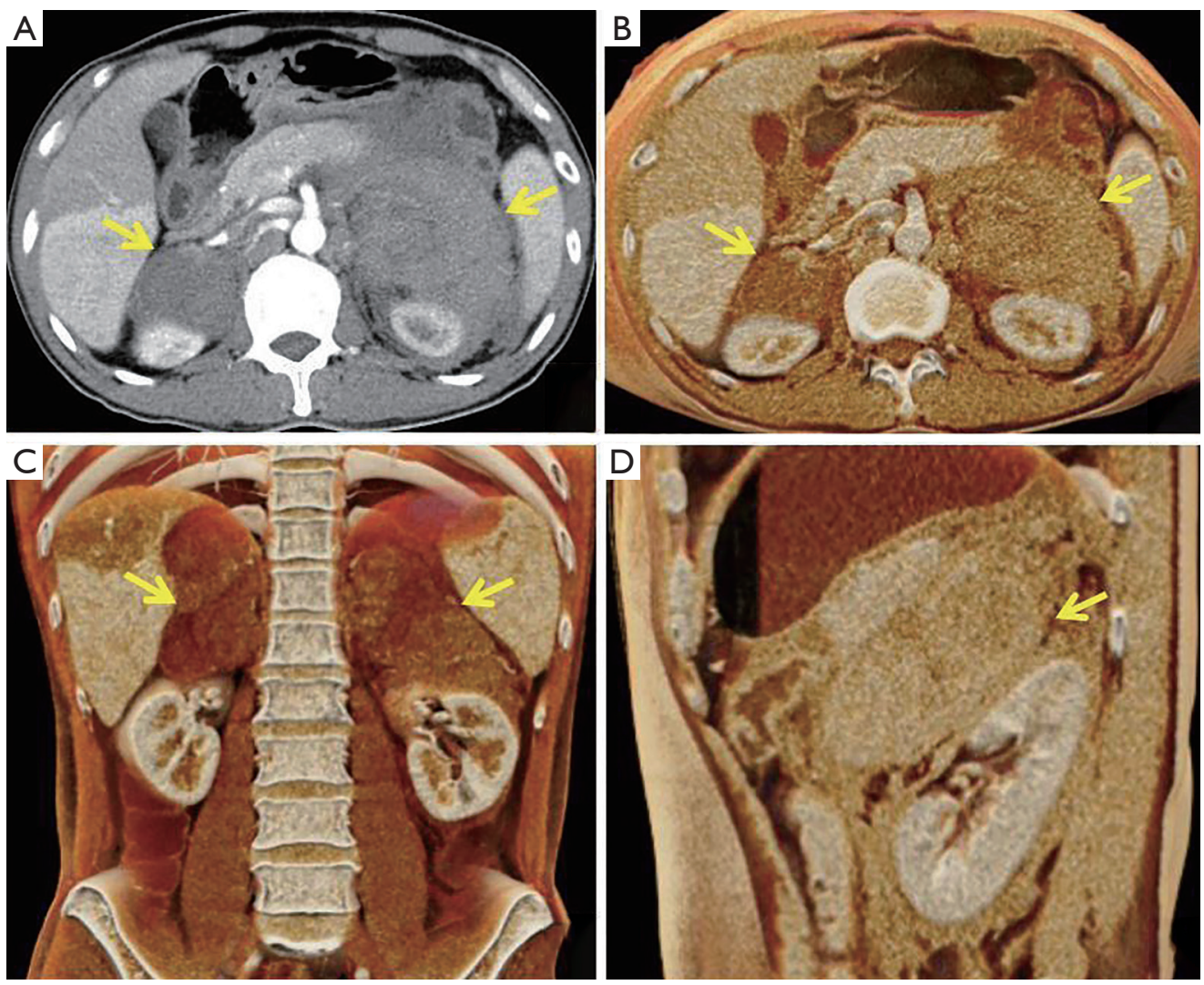

Figure 9 Lymphoma. A 44-year-old man with left lumbar and abdominal pain for 1 hour. (A,B) Axial position: at the arterial stage, bilateral perirenal soft tissue density shadows (yellow arrows) are uniformly intensified. The left mass is larger and encircles the entire left kidney, while the right mass is smaller and located in front of the right kidney. (C) In the coronal position, most of the masses are located over both kidneys. (D) In the sagittal position, the left mass surrounds the left kidney.

of lymphoma in different planes (Figure 9), providing comprehensive diagnostic information for clinicians.

\section{Adrenal metastases}

The metastatic tumor is the most common malignant tumor of the adrenal gland, and its primary foci are lung cancer and breast cancer, followed by cancer of the thyroid, stomach, pancreas, colon, and malignant melanoma. The metastatic tumor may be unilateral or bilateral, is generally small, but can also be unilaterally large. Its cell composition and enhancement pattern are often associated with primary cancer, usually without calcification $(4,21,52)$. CR rendering imaging simultaneously shows the primary tumor and unilateral or bilateral adrenal metastases in the same plane and has a tremendous visual impact on physicians and patients (Figure 10). Vividly and concretely presenting detailed information of the disease with a single image will facilitate effective doctor-patient communication and contribute to the understanding of the disease among interns and junior doctors.

\section{Conclusions}

CR simulates the physical transmission of light in different environments in the real world, giving colorful vitality to the black-and-white image world. It presents the fine anatomical structures of different parts of the human body realistically and vividly, giving clinicians and patients a deeper perception. It also shows good potential application value in adrenal tumor localization, diagnosis, differential diagnosis, preoperative planning, teaching, and doctorpatient communication, which needs to be further verified in future studies. 

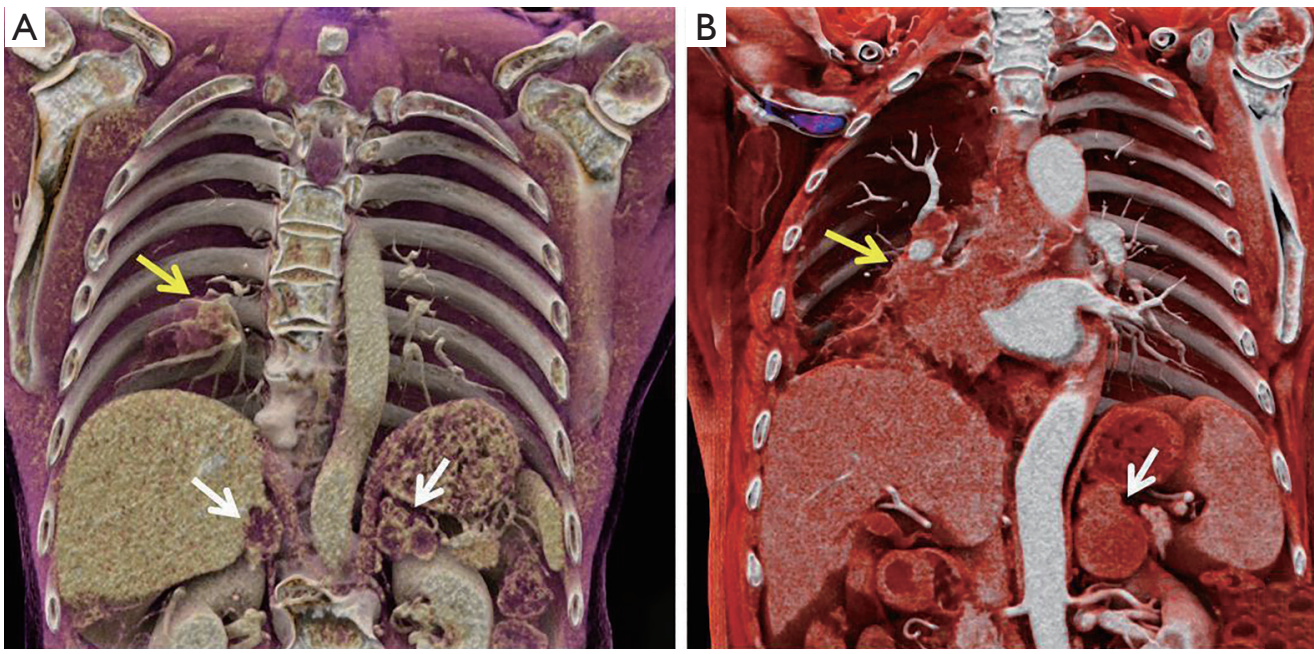

Figure 10 Adrenal Metastases. (A) A 60-year-old man with adenocarcinoma of the right lower lung. Coronal CT demonstrates a mass in the lower lobe of the right lung and multiple nodules in bilateral adrenal glands. (B) A 76-year-old man with squamous cell carcinoma of the right lung. CT image shows an irregular mass in the mediastinum and right lower lung portal area, encircling the heart and large vessels, obstructing the right lower lobe bronchus, along with a lobulated mass in the left adrenal region (yellow arrow: lung mass; white arrow: adrenal metastatic tumor).

\section{Acknowledgments}

Funding: This study was supported by the Guizhou Science and Technology Foundation Project \{QKHPTRC[2019]5803, QKHZC [2 018 ] 2 793, QKHJC[2 017 ] 1109 , and QKHPTRC[2017]5724\}, Guizhou Science and Technology Department Key Lab Project $\{\mathrm{QKF}[2017] 25\}$, and National Natural Science Foundation Project (NO. 82060314).

\section{Footnote}

Conflicts of Interest: All authors have completed the ICMJE uniform disclosure form (available at http:// dx.doi.org/10.21037/qims-20-1282). GL reports grant from Guizhou Science and Technology Foundation Project \{QKHZC[2018]2793\}. XZ reports grants from Guizhou Science and Technology Foundation Project \{QKHJC[2017]1109\} and National Natural Science Foundation Project (NO. 82060314). Rongpin Wang reports grants from Guizhou Science and Technology Foundation Project \{QKHPTRC[2019]5803\}, Guizhou Science and Technology Foundation Project \{QKHPTRC[2017]5724\}, and Guizhou Science and Technology Department Key Lab Project \{QKF[2017]25\}. The other authors have no conflicts of interest to declare.
Ethical Statement: The authors are accountable for all aspects of the work in ensuring that questions related to the accuracy or integrity of any part of the work are appropriately investigated and resolved.

Open Access Statement: This is an Open Access article distributed in accordance with the Creative Commons Attribution-NonCommercial-NoDerivs 4.0 International License (CC BY-NC-ND 4.0), which permits the noncommercial replication and distribution of the article with the strict proviso that no changes or edits are made and the original work is properly cited (including links to both the formal publication through the relevant DOI and the license). See: https://creativecommons.org/licenses/by-nc-nd/4.0/.

\section{References}

1. Glazer DI, Mayo-Smith WW. Management of incidental adrenal masses: an update. Abdom Radiol (NY) 2020;45:892-900.

2. Young $\mathrm{Jr} \mathrm{W}$ F. The incidentally discovered adrenal mass. N ENGL J MED 2007;356:601-10.

3. Mayo-Smith WW, Song JH, Boland GL, Francis IR, Israel GM, Mazzaglia PJ, Berland LL, Pandharipande PV. Management of Incidental Adrenal Masses: A White Paper 
of the ACR Incidental Findings Committee. J Am Coll Radiol 2017;14:1038-44.

4. Jason DS, Oltmann SC. Evaluation of an Adrenal Incidentaloma. Surg Clin North Am 2019;99:721-9.

5. Blake M A, Kalra M K, Sweeney A T, Lucey S B, Maher M M, Sahani D V, Halpern E F, Mueller P R, Hahn P $\mathrm{F}$, Boland G W. Distinguishing benign from malignant adrenal masses: multi-detector row CT protocol with 10-minute delay. Radiology 2006;238:578-85.

6. Costa AD Jr, Gellada N. Cinematic rendering for threedimensional reconstructions of the chest wall: a new reality. Einstein 2020;18:eMD5223.

7. Eid M, De Cecco CN, Nance JW Jr, Caruso D, Albrecht MH, Spandorfer AJ, De Santis D, VargaSzemes A, Schoepf UJ. Cinematic Rendering in CT: A Novel, Lifelike 3D Visualization Technique. AJR Am J Roentgenol 2017;209:370-9.

8. Forte E, Infante T, Baldi D, Salvatore M, Cademartiri F, Cavaliere C. A case of coronary arterio-venous fistula: the role of cardiac computed tomography. J Thorac Dis 2018;10:E699-E703.

9. Forte E, Punzo B, Agrusta M, Salvatore M, Spidalieri G, Cavaliere C. A case report of right coronary artery agenesis diagnosed by computed tomography coronary angiography. Medicine 2020;99:e19176.

10. Fellner F A. Introducing cinematic rendering: a novel technique for post-processing medical imaging data. J Biomed Sci Eng 2016;9:170-5.

11. Colli A, Tua L, Punzo B, Baldi D, Cademartiri F, Gerosa G. Cinematic rendering: an alternative to classical volume rendering for acute aortic dissection. Ann Thorac Surg 2019;108:e121.

12. Baldi D, Tramontano L, Punzo B, Orsini M, Cavaliere C. CT cinematic rendering for glomus jugulare tumor with intracranial extension. Quant Imaging Med Surg 2020;10:522-6.

13. Chu LC, Fishman EK. Quadricuspid Aortic Valve: Cinematic Rendering. Radiology 2018;288:658.

14. Chu LC, Rowe SP, Fishman EK. Cinematic rendering of focal liver masses. Diagn Interv Imaging 2019;100:467-76.

15. Rowe SP, Chu LC, Fishman EK. Initial experience with 3D CT cinematic rendering of acute pancreatitis and associated complications. Abdom Radiol (NY) 2020;45:1290-8.

16. Rowe SP, Chu LC, Fishman EK. 3D CT cinematic rendering of the spleen: Potential role in problem solving. Diagn Interv Imaging 2019;100:477-83.

17. Rowe SP, Fishman EK. Cinematic Rendering of
Neurofibromatosis Type I Gastrointestinal Stromal Tumors. Radiology 2019;291:298.

18. Jhala K, Madan R, Hammer M. A pictorial review of lung torsion using 3D CT cinematic rendering. Emerg Radiol 2021;28:171-6.

19. Karstaedt N, Sagel SS, Stanley RJ, Melson GL, Levitt RG. Computed tomography of the adrenal gland. Radiology 1978;129:723-30.

20. Gokan T, Ohgiya Y, Nobusawa H, Munechika H. Commonly encountered adrenal pseudotumours on CT. Br J Radiol 2005;78:170-4.

21. Elsayes KM, Elmohr MM, Javadi S, Menias CO, Remer EM, Morani AC, Shaaban A. Mimics, pitfalls, and misdiagnoses of adrenal masses on CT and MRI. Abdom Radiol (NY) 2020;45:982-1000.

22. Boland GW, Lee MJ, Gazelle GS, Halpern EF, McNicholas MM, Mueller PR. Characterization of adrenal masses using unenhanced CT: an analysis of the CT literature. AJR Am J Roentgenol 1998;171:201-4.

23. Yamada T, Ishibashi T, Saito H, Matsuhashi T, Majima K, Tsuda M, Takahashi S, Moriya T. Adrenal adenomas: relationship between histologic lipid-rich cells and CT attenuation number. Eur J Radiol 2003;48:198-202.

24. Caoili E M, Korobkin M, Francis I R, Cohan RH, Dunnick NR. Delayed enhanced CT of lipid-poor adrenal adenomas. AJR Am J Roentgenol 2000;175:1411-5.

25. Thomas AJ, Habra MA, Bhosale PR, Qayyum AA, Ahmed $\mathrm{K}$, Vicens R, Elsayes KM. Interobserver agreement in distinguishing large adrenal adenomas and adrenocortical carcinomas on computed tomography. Abdom Radiol (NY) 2018;43:3101-8.

26. Lenders JW, Duh QY, Eisenhofer G, Gimenez-Roqueplo AP, Grebe SK, Murad MH, Naruse M, Pacak K, Young WF Jr; Endocrine Society. Pheochromocytoma and paraganglioma: an endocrine society clinical practice guideline. J Clin Endocrinol Metab 2014;99:1915-42.

27. Lenders JW, Eisenhofer G, Mannelli M, Pacak K. Phaeochromocytoma. Lancet 2005;366:665-75.

28. Fassnacht M, Arlt W, Bancos I, Dralle H, Newell-Price J, Sahdev A, Tabarin A, Terzolo M, Tsagarakis S, Dekkers OM. Management of adrenal incidentalomas: European society of endocrinology clinical practice guideline in collaboration with the European network for the study of adrenal tumors. Eur J Endocrinol 2016;175:G1-G34.

29. Canu L, Van Hemert JAW, Kerstens MN, Hartman RP, Khanna A, Kraljevic I, Kastelan D, Badiu C, Ambroziak U, Tabarin A, Haissaguerre M, Buitenwerf E, Visser A, Mannelli M, Arlt W, Chortis V, Bourdeau I, Gagnon N, 
Buchy M, Borson-Chazot F, Deutschbein T, Fassnacht M, Hubalewska-Dydejczyk A, Motyka M, Rzepka E, Casey RT, Challis BG, Quinkler M, Vroonen L, Spyroglou A, Beuschlein F, Lamas C, Young WF, Bancos I, Timmers HJLM. CT Characteristics of Pheochromocytoma: Relevance for the Evaluation of Adrenal Incidentaloma. J Clin Endocrinol Metab 2019;104:312-8.

30. Plouin P F, Fitzgerald P, Rich T, Ayala-Ramirez M, Perrier ND, Baudin E, Jimenez C. Metastatic pheochromocytoma and paraganglioma: focus on therapeutics. Horm Metab Res 2012;44:390-9.

31. Caoili EM, Korobkin M, Francis IR, Cohan RH, Platt JF, Dunnick NR, Raghupathi KI. Adrenal masses: characterization with combined unenhanced and delayed enhanced CT. Radiology 2002;222:629-33.

32. Blake MA, Krishnamoorthy SK, Boland GW, Sweeney AT, Pitman MB, Harisinghani M, Mueller PR, Hahn PF. Lowdensity pheochromocytoma on CT: a mimicker of adrenal adenoma. AJR Am J Roentgenol 2003;181:1663-8.

33. Daneshmand S, Quek M L. Adrenal myelolipoma: diagnosis and management. Urol J 2006;3:71-4.

34. Osborn M, Smith M, Senbanjo T, Crofton M, Robinson S, Rajan P. Adrenal myelolipoma-clinical, radiological and cytological findings: a case report. Cytopathology 2002;13:242-6.

35. Ioannidis O, Papaemmanouil S, Chatzopoulos S, Paraskevas G, Konstantara A, Kotronis A, Kakoutis E, Makrantonakis A. Giant Bilateral Symptomatic Adrenal Myelolipomas Associated with Congenital Adrenal Hyperplasia. Pathol Oncol Res 2011;17:775-8.

36. Degheili JA, Abou Heidar NF, El-Moussawi M, Tawil A, Nasr RW. Adrenal Cavernous Hemangioma: A Rarely Perceived Pathology-Case Illustration and Review of Literature. Case Rep Pathol 2019; 2019:8463890.

37. Yamada T, Ishibashi T, Saito H, Majima K, Tsuda M, Takahashi S, Moriya T. Two cases of adrenal hemangioma: CT and MRI findings with pathological correlations. Radiat Med 2002;20:51-6.

38. Zhou J, Zhang D, Li W, Zhou L, Xu H, Zheng S, Wang C. Primary adrenal schwannoma: a series of 31 cases emphasizing their clinicopathologic features and favorable prognosis. Endocrine 2019;65:662-74.

39. Zhang YM, Lei PF, Chen MN, Lv XF, Ling YH, Cai PQ, Gao JM. CT findings of adrenal schwannoma. Clin Radiol 2016;71:464-70.

40. Tang W, Yu XR, Zhou LP, Gao HB, Wang QF, Peng WJ. Adrenal schwannoma: CT, MR manifestations and pathological correlation. Clin Hemorheol Microcirc
2018;68:401-12.

41. Wanis KN, Kanthan R. Diagnostic and prognostic features in adrenocortical carcinoma: a single institution case series and review of the literature. World J Surg Oncol 2015;13:117.

42. Ayala-Ramirez M, Jasim S, Feng L, Ejaz S, Deniz F, Busaidy N, Waguespack SG, Naing A, Sircar K, Wood CG, Pagliaro L, Jimenez C, Vassilopoulou-Sellin R, Habra M. Adrenocortical carcinoma: clinical outcomes and prognosis of 330 patients at a tertiary care center. Eur J Endocrinol 2013;169:891-9.

43. Sinclair TJ, Gillis A, Alobuia WM, Wild H, Kebebew E. Surgery for adrenocortical carcinoma: When and how? Best Pract Res Clin Endocrinol Metab 2020;34:101408.

44. Ahmed AA, Thomas AJ, Ganeshan DM, Blair KJ, Lall C, Lee JT, Morshid AI, Habra MA, Elsayes KM. Adrenal cortical carcinoma: pathology, genomics, prognosis, imaging features, and mimics with impact on management. Abdom Radiol (NY) 2020;45:945-963.

45. Brisse HJ, McCarville MB, Granata C, Krug KB, Wootton-Gorges SL, Kanegawa K, Giammarile F, Schmidt M, Shulkin BL, Matthay KK, Lewington VJ, Sarnacki S, Hero B, Kaneko M, London WB, Pearson AD, Cohn SL, Monclair T; International Neuroblastoma Risk Group Project. Guidelines for imaging and staging of neuroblastic tumors: consensus report from the International Neuroblastoma Risk Group Project. Radiology 2011;261:243-57.

46. Dumba M, Jawad N, McHugh K. Neuroblastoma and nephroblastoma: a radiological review. Cancer Imaging 2015;15:5.

47. Lanza C, Galeazzi V, Carboni N, De Berardinis A, De Marino L, Barile A, Giovagnoni A. Neuroblastoma imagedefined risk factors in adrenal neuroblastoma: role of radiologist. Gland Surg 2019;8:S168-S177.

48. Monclair T, Brodeur GM, Ambros PF, Brisse HJ, Cecchetto G, Holmes K, Kaneko M, London WB, Matthay KK, Nuchtern JG, von Schweinitz D, Simon T, Cohn SL, Pearson AD; INRG Task Force. The international neuroblastoma risk group (INRG) staging system: an INRG task force report. J Clin Oncol 2009;27:298-303.

49. Cohn SL, Pearson AD, London WB, Monclair T, Ambros PF, Brodeur GM, Faldum A, Hero B, Iehara T, Machin D, Mosseri V, Simon T, Garaventa A, Castel V, Matthay KK; INRG Task Force. The International Neuroblastoma Risk Group (INRG) classification system: an INRG task force report. J Clin Oncol 2009;27:289-97. 
50. Laurent C, Casasnovas O, Martin L, Chauchet A, Ghesquieres H, Aussedat G, Fornecker LM, Bologna S, Borot S, Laurent K, Bouillet B, Verges B, Petit JM. Adrenal lymphoma: presentation, management and prognosis. QJM 2017;110:103-109.

51. Yang L, Zhang M, Zhao S, Hu Y, Yao J. Correlations between MDCT features and clinicopathological

Cite this article as: Tang L, Wang Y, Yang X, Luo G, Zeng X, Wang R, Song B. Virtual or real: lifelike cinematic rendering of adrenal tumors. Quant Imaging Med Surg 2021;11(8):3854-3866. doi: 10.21037/qims-20-1282 findings of primary adrenal lymphoma. Eur J Radiol 2019;113:110-5.

52. Choi YA, Kim CK, Park BK, Kim B. Evaluation of adrenal metastases from renal cell carcinoma and hepatocellular carcinoma: use of delayed contrast-enhanced CT.

Radiology 2013;266:514-20. 